\title{
Erratum to: RNA-Seq and Expression Arrays: Selection Guidelines for Genome-Wide Expression Profiling
}

\author{
Jessica Minnier, Nathan D. Pennock, Qiuchen Guo, Pepper Schedin, \\ and Christina A. Harrington
}

\section{Erratum to:}

Chapter 2 in: Nalini Raghavachari and Natàlia Garcia-Reyero (eds.),

Gene Expression Analysis: Methods and Protocols,

Methods in Molecular Biology, vol. 1783,

https://doi.org/10.1007/978-1-4939-7834-2_2

The original version of the book was inadvertently published with incorrect spelling of the author name "Qiuchen Guo" corrections. The author name has now been corrected and approved by the author. 